\title{
Analysis of the Competition for the Location of the Optimal Hub in the WAEMU (West African Economic and Monetary Union) Zone
}

\author{
Abdoulaye Ali Ibrahima ${ }^{1}$, Saley Bisso ${ }^{1,2}$, Salimata Gueye Diagne ${ }^{1}$, C. Diallo ${ }^{2}$ \\ ${ }^{1}$ Universite Cheikh Anta Diop de Dakar(Senegal) \\ ${ }^{2}$ Universite Abdou Moumouni de Niamey (Niger) \\ Correspondence: Abdoulaye Ali Ibrahima, Cheikh Anta Diop University, Dakar Senegal
}

Received: January 14, 2021 Accepted: March 17, 2021 Online Published: April 20, 2021

doi:10.5539/jmr.v13n3p45 URL: https://doi.org/10.5539/jmr.v13n3p45

\begin{abstract}
The objective of this study is to analyze the contribution of governance (political stability) as well as per capita income and traffic past measured through the number of passengers traveling by air during a period of one year within each country of the zone to the formation of a hub in the WAEMU zone. Governance has been apprehended through Kaufman indicators which summarize the six dimensions of governance. Three control variables have been added in the model to better explain per capita income and reduce bias in the estimation. To achieve this objective, the study proceeded first with a descriptive analysis which revealed the existence of a positive linear correlation between governance indicators and the level of air traffic, and then with a dynamic panel approach. To this end, the Generalized Moment Method (GMM) showed that the overall contribution of governance to economic performance is not significant in the sample, as well as for each dimension of governance taken individually. However, the results differ when dissociating the specific effect of Senegal, where political stability, government effectiveness, regulatory quality and rules and laws each have a positive and significant impact on per capita income.
\end{abstract}

Keywords: governance, economic performance, generalized method of moments

\section{Introduction}

\subsection{Introduce the Problem}

A hub is an airport connection platform. The choice of its location consists in determining the ideal location of the airport in order to optimize economic function. This can depend on the distances between the airports, the cost of extension of the airport, of the cost of transport per unit of distance, it integrates the costs operating conditions of K?eroz'ene, the number of passengers registered at the airport etc. Many researchers have worked on the problem of air transport in general and in particular on the location of hubs. A state of the art on the localization problem of the hubs was drawn up by (A. Sibel and Y. KARA., 2007) and by (CAMPELL J.F.,). A linearization of this formumlation is given by (CAMPELL., 1994). (Ivan Contreras et al., 2011) used Branch and price and Lagrangian relaxation for the problem of location and unique assignment of a hub with a large capacity. (C. Diallo et al., 2012) worked on the scheduling of landing stages at L?eopold Sedar airport SENGOR from Dakar. (Lap?gue Tanguy et all., 2013) have developed a mathematical model for staff scheduling with task assignment and using localization to present an industrial problem. (O'Kelly., 1987) gives a quadratic formulation of the entire program of locating a hub without capacity with single assignment. (Rodriguez et al., 2007) have solved the problem of localization and allocation unique of a hub with high capacity by Branch and Price.All these authors, the list of which is not exhaustive, have made a contribution in the air transport system, but so far none of the authors have taken into account the political stability of the countries. which is an important criterion for investors. And also almost no specific contribution for the UEMOA zone (N?DOGOTAR N?elio et al., 2015) have solved a model for locating a hub air, which minimizes the distances traveled by taking into account the flow of passengers registered in the airports of the UEMOA zone.In this article, we bring our contribution in the management of the air transport system in the UEMOA zone by proposing and by simulating a model of localization of an air hub by a dynamic panel approach, which analyzes the contribution of governance (political stability) as well as per capita income and air traffic measured through the number of passengers who travel by plane during a period of one year within each countries of the zone to the formation of a hub in the WAEMU zone and we use the Stata software for the simulation. 


\subsection{Position of the Problem}

The principle of the hub is to allow the connection of a large number of small traffic flows (short and medium haul) to larger flows to and from the international (long haul). Several times a day, this involves creating appointment slots on which the arrivals and departures of flights are concentrated. This allows passengers to transfer quickly and easily. This organization by time slots increases the opportunities for correspondence with a minimum waiting time between two flights, making travel and the use of airplanes profitable. At the hub level, maintenance problems are also quite often resolved. The choice of an airport by a company to make it a hub owes nothing to chance. The hub must be well positioned in relation to the flow of traffic. Passengers must in fact avoid too great a detour. The hub must be located in a region which itself generates a high demand for air transport, in order to contribute to the filling of planes and to the geographical diversity of the proposed routes. As a result, most hubs are located close to major urban agglomerations, especially if these concentrate international economic functions. The hub airport must have sufficient capacity, both to expand the offer and to organize timetables as freely possible and thus effectively coordinate flights. However, for the development of any good business, political stability is one of the parameters that attracts investors much more, especially in our African countries. We consider here the eight countries of the WAEMU zone: Benin, Burkina Faso, Cote d'Ivoire, Guinea Bissau, Mali, Niger, Senegal and Togo, represented by their international airport. capital city.

\section{Description of Variables and Presentation of the Sample}

The objective of this section is to present the different variables that will be the subject of econometric modeling according to the literature review.

\subsection{Dependent Variable}

The dependent variable of our study is air traffic as measured by the number of passengers who travel by air during a period of one year within each country of the zone.

\subsection{Explanatory Variables}

Voice and Account: measured by the degree of participation of a country's citizens in choosing their government, freedom of expression, association and the press;

Political Stability and Absence of Violence (Political Stability): measured by the risk that a government will be destabilized by unconstitutional means or by violence, including terrorism;

Government Effectivness: measured by the quality of public services, the quality of civil services and their independence from political pressure and the quality of the policies put in place.

Regulatory Quality: measured by a government's ability to provide policies and regulations that enable and promote private sector development;

Rule of Law: measured by the level of trust and confidence that officials have in the laws of the land, respect for society and respect for the police and the courts;

Control of Corruption: as measured by the fac?on by which public power is exercised for private purposes, including minor forms of corruption, 'corruption in the form of bribery, corruption in the public sector, and corruption in the private sector, as well as the misappropriation of state assets by the elites.

\section{Description of the Variables and Presentation of the Sample}

The sample used in this work is made up of annual data from the seven countries of the West African Monetary and Economic Union (WAEMU), the eighth being Guinea Bissau was removed from the sample due to the lack of observations on certain indicators over the period. The variables used are those detailed in the previous section. These variables cover the period from 2002 to 2017 and come from the World Bank database (World Development Indicators (http://data.worldbank.org/indicator)). The selection of this period is constrained by the lack of observations of certain variables from previous years for most countries.

The table above presents descriptive statistics of the variables by country. On average, the highest levels of passenger numbers per country are observed in C?te d'Ivoire (324999.8) and Senegal (349666.3) while the lowest values are in Togo (578545.6). The highest level of per capita income is observed in Senegal over this period (2665.05) and C?te d'Ivoire (2287.47) against (817.54) for Niger. On the other hand, the highest level of financial development is observed in Togo (23.99), while the lowest is observed in Niger (10.38). As for energy consumption, the highest values are observed in Guinea Bissau (88.66). In addition to financial development, Togo is the country with the highest rate of trade openness in the zone. Subsequently, Mali has the least stable level compared to other countries in terms of economic output. Indeed, its coefficient of variation is the highest $(0.42)$ as measured by the standard deviation/average ratio. In terms of $\mathrm{CO} 2$ 
Table 1. Description of variables and risk analysis

\begin{tabular}{|c|c|c|c|c|c|c|c|c|c|}
\hline country & descriptive statistics & Trafic & Rnb/Hab & $\mathbf{V A}$ & PS & $\overline{\text { GE }}$ & RQ & $\mathbf{R L}$ & $\mathbf{C C}$ \\
\hline \multirow[t]{3}{*}{$3[6] *$ Benin } & Mean & 65468,45 & 1829,33 & 0,2 & 0,33 & $\begin{array}{l}-0,49 \\
\end{array}$ & $-0,44$ & $\begin{array}{l}-0,58 \\
\end{array}$ & $-0,69$ \\
\hline & $\mathrm{sd}$ & 29565,63 & 98,57 & 0,11 & 0,2 & 0,08 & 0,08 & 0,08 & 0,14 \\
\hline & $\mathrm{CV}$ & 0,45 & 0,05 & 0,55 & 0,61 & $-0,16$ & $-0,18$ & $-0,14$ & $-0,2$ \\
\hline \multirow[t]{3}{*}{$3[6]^{*}$ Burkina Faso } & Mean & 99302,02 & 1380,95 & $-0,34$ & $-0,28$ & $-0,61$ & $-0,23$ & $-0,44$ & $-0,32$ \\
\hline & sd & 36501,82 & 143,7 & 0,07 & 0,37 & 0,07 & 0,1 & 0,13 & 0,17 \\
\hline & $\mathrm{CV}$ & 0,37 & 0,1 & $-0,21$ & $-1,32$ & $-0,11$ & $-0,43$ & $-0,3$ & $-0,53$ \\
\hline \multirow{3}{*}{$3[6]^{*}$ Cote d'Ivoire } & Mean & 324999,8 & 2287,47 & $-1,04$ & $-1,56$ & 1,07 & $-0,78$ & $-1,21$ & $-0,93$ \\
\hline & sd & 173196,3 & 678,27 & 0,3 & 0,45 & 0,19 & 0,16 & 0,31 & 0,26 \\
\hline & $\mathrm{CV}$ & 0,53 & 0,3 & $-0,29$ & $-0,29$ & 0,18 & $-0,21$ & $-0,26$ & $-0,28$ \\
\hline \multirow[t]{3}{*}{$3[6] *$ Mali } & Mean & 187224,2 & 1752,98 & 0,04 & $-0,51$ & $-0,79$ & $-0,46$ & $-0,36$ & $-0,57$ \\
\hline & $\mathrm{sd}$ & 88898,53 & 86,42 & 0,27 & 0,93 & 0,14 & 0,06 & 0,25 & 0,13 \\
\hline & $\mathrm{CV}$ & 0,47 & 0,05 & 6,75 & $-1,82$ & $-0,18$ & $-0,13$ & $-0,69$ & $-0,23$ \\
\hline \multirow[t]{3}{*}{$3[6]^{*}$ Niger } & Mean & 106919,14 & 817,54 & $-0,36$ & $-0,77$ & $-0,71$ & $-0,52$ & $-0,72$ & $-0,73$ \\
\hline & sd & 67548,47 & 44,8 & 0,17 & 0,42 & 0,07 & 0,17 & 0,16 & 0,16 \\
\hline & $\mathrm{CV}$ & 0,63 & 0,05 & $-0,47$ & $-0,55$ & $-0,1$ & $-0,33$ & $-0,22$ & $-0,22$ \\
\hline \multirow{3}{*}{$3[6] *$ Senegal } & Mean & 349666,3 & 2665,05 & $-0,002$ & $-0,21$ & $-0,34$ & $-0,22$ & $-0,25$ & $-0,25$ \\
\hline & sd & 191267,6 & 140,1 & 0,23 & 0,11 & 0,15 & 0,08 & 0,28 & 0,28 \\
\hline & $\mathrm{CV}$ & 0,55 & 0,05 & -115 & $-0,52$ & $-0,44$ & $-0,36$ & $-1,12$ & $-1,12$ \\
\hline \multirow[t]{3}{*}{$3[6] *$ Togo } & Mean & 578545,6 & 1281,77 & $-1,08$ & $-0,34$ & $-1,4$ & 0,86 & $-0,99$ & $-0,89$ \\
\hline & sd & 141867,3 & 140,8 & 0,19 & 0,33 & 0,13 & 0,08 & 0,21 & 0,22 \\
\hline & $\mathrm{CV}$ & 0,25 & 0,11 & $-0,18$ & $-0,97$ & $-0,09$ & 0,09 & $-0,21$ & $-0,25$ \\
\hline
\end{tabular}

emissions, Benin is the most volatile because it has the highest coefficient of variation (0.38) compared to other countries. The same trends are found for financial development (0.46), trade openness $(0.22)$ and energy consumption (0.18) for Guinea Bissau and Burkina Faso respectively.

\subsection{Correlation Matrix Between the Different Variables and Our Dependent Variable}

Table 2. Correlation matrix

\begin{tabular}{lcccccccc}
\hline Variables & Trafic & Rnbhab & VA & PS & GE & RQ & RL & CC \\
\hline Trafic & 1 & & & & & & & \\
Rnbhab & 0,1913 & 1 & & & & & & \\
VA & $-0,5343^{*}$ & 0,2232 & 1 & & & & & \\
PS & $-0,1222$ & 0,0117 & $0,6075^{*}$ & 1 & & & & \\
GE & $-0,5013^{*}$ & $0,3159^{*}$ & $0,8288^{*}$ & $0,4318^{*}$ & 1 & & & \\
RQ & $-0,4345^{*}$ & 0,1971 & $0,6939^{*}$ & $0,4178^{*}$ & $0,7969^{*}$ & 1 & & \\
RL & $-0,3469^{*}$ & 0,225 & $0,8098^{*}$ & $0,5210^{*}$ & $0,7353^{*}$ & $0,7249^{*}$ & 1 & \\
CC & $-0,2655^{*}$ & 0,2485 & $0,5731^{*}$ & $0,3872^{*}$ & $0,6910^{*}$ & $0,7210^{*}$ & $0,7583^{*}$ & 1 \\
\hline
\end{tabular}

As the aim of this article is to explain the number of passengers per year in each country of the zone through the other variables, it is necessary to study beforehand the connections between these different variables. The aim is to study the existence of correlations between the explanatory variables and the explained variable on the one hand, and between the explanatory variables themselves on the other. Indeed, since we will proceed by regression with the Generalized Moment Method (GMM), it will be necessary to ensure the absence of multicollinearity between the explanatory variables. We will therefore use the correlation matrix of all the variables to assess their level of association with air traffic. The table below shows that Income per capita is the only variable with a positive correlation with air traffic, even if this link is weak. Thereafter, voice and government accountability and effectiveness are more than moderately correlated with the dependent variable in a negative way. The rest of the variables are also negatively correlated with the dependent variable, but at lower orders than the two previous ones.

\subsection{Factor Analysis}

Principal Component Analysis (PCA) allows the visualization of a data set containing individuals described by several quantitative variables. It is a statistical method that allows the exploration of the behavior of a sample of individuals according to their associations across several variables. The Cloud of Individuals can thus illustrate the distance between countries in the sample according to their similarities or dissimilarities and the associations between governance variables, per capita income and air traffic levels.

At the end of the PCA, it appears that the first two factorial axes alone concentrate $75 \%$ of the total inertia and they both have an eigenvalue greater than 1 . Given this proportion, the eigenvalue associated with them and the successive 
differences between these eigenvalues, these two axes summarize most of the information contained in all the variables.

Table 3. Add caption

\begin{tabular}{lcccr}
\hline Factors & eigenvalues & Differences & Proportion & cumulative \\
\hline Comp1 & 4.5 & 3.5 & 0.6 & 0.6 \\
Comp2 & 1.5 & 0.3 & 0.2 & 0.7 \\
Comp3 & 1.3 & 0.8 & 0.2 & 0.9 \\
Comp4 & 0.4 & 0.2 & 0.1 & 0.9 \\
Comp5 & 0.3 & 0.2 & 0.1 & 1 \\
Comp6 & 0.1 & 0.1 & 0 & 1 \\
Comp7 & 0 & 0 & 0 & 1 \\
Comp8 & 0 & 0 & 0 & 1 \\
\hline
\end{tabular}

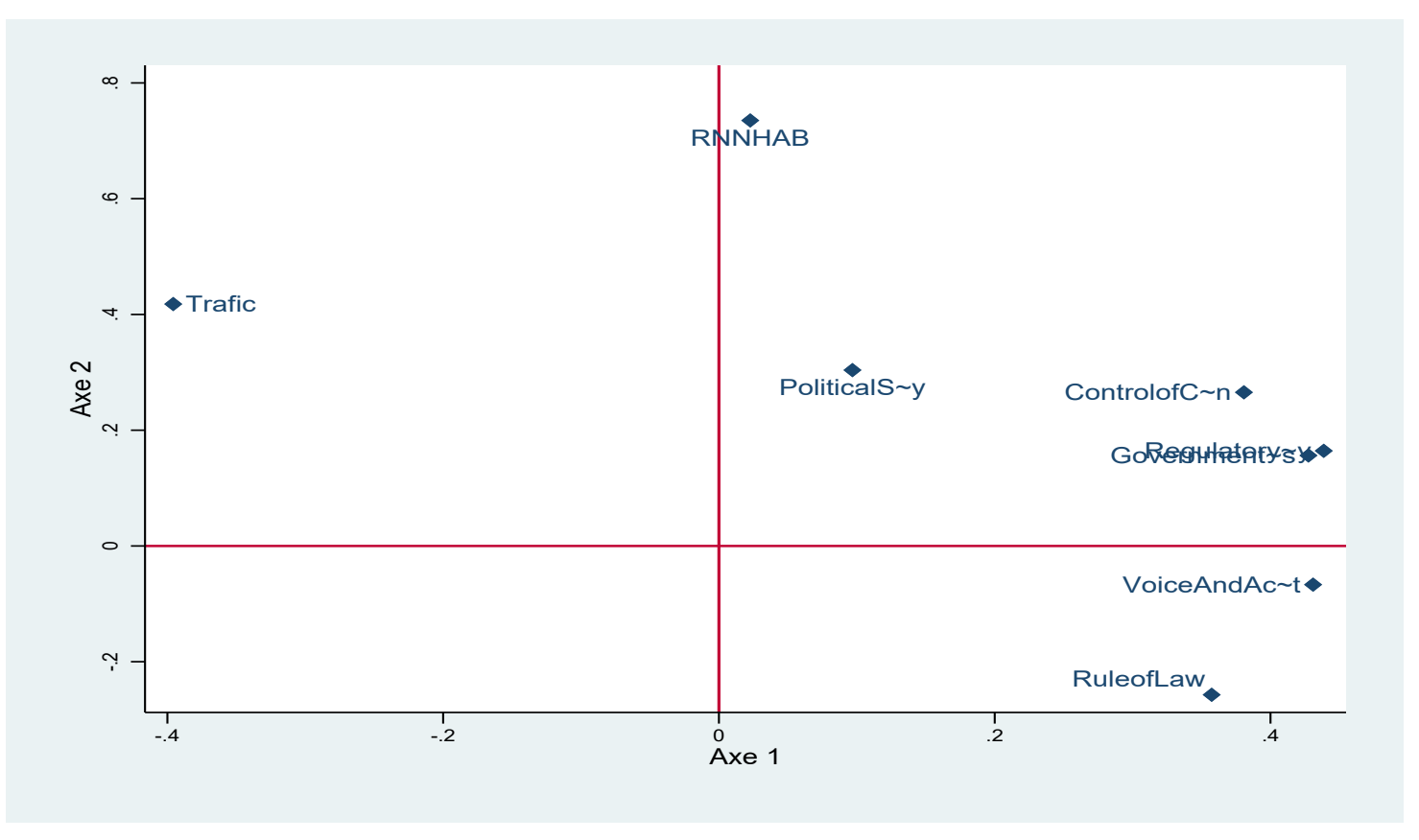

Figure 1. Cloud of variables from PCA

Source: author

The figure above characterizes the study variables according to their associations in the design formed by the first two factorial axes. This factorial design does not seem to reflect any real correlation between traffic intensity and governance variables.

Nevertheless, the first factor axis characterizes countries with a high level of per capita income and good political stability. Axis 2 characterizes countries with good governance and institutional stability on the one hand, and a high volume of air traffic on the other.

Source: autor The figure above shows clusters of countries with relatively similar characteristics according to governance variables, per capita income and air traffic intensity. Thus, two groups of countries emerge: Burkina Faso and Benin and Niger and Mali. Depending on each group, these countries present similarities with regard to the above-mentioned variables. Cote d'Ivoire, Togo and Senegal have singular behaviors due to the fact that they have an average GHAbR and good governance (Senegal) or a low (Togo) or high (Cote d'Ivoire) GHAbR and poor governance.

\section{Econometric Modeling of Air Traffic in the WAEMU Zone}

The purpose of this section is to estimate the impact of the governance indicators and the economic performance recorded by these countries on the number of passengers per year, for our sample. The regression of the study variable (Traffic) as a function of the explanatory variables considered relevant, the results of which are given in the table below, shows that the model is globally significant ( $\operatorname{prob}_{i} \mathrm{~F}=0,0000$ ). However, we note that only the Compliance with laws and rules 


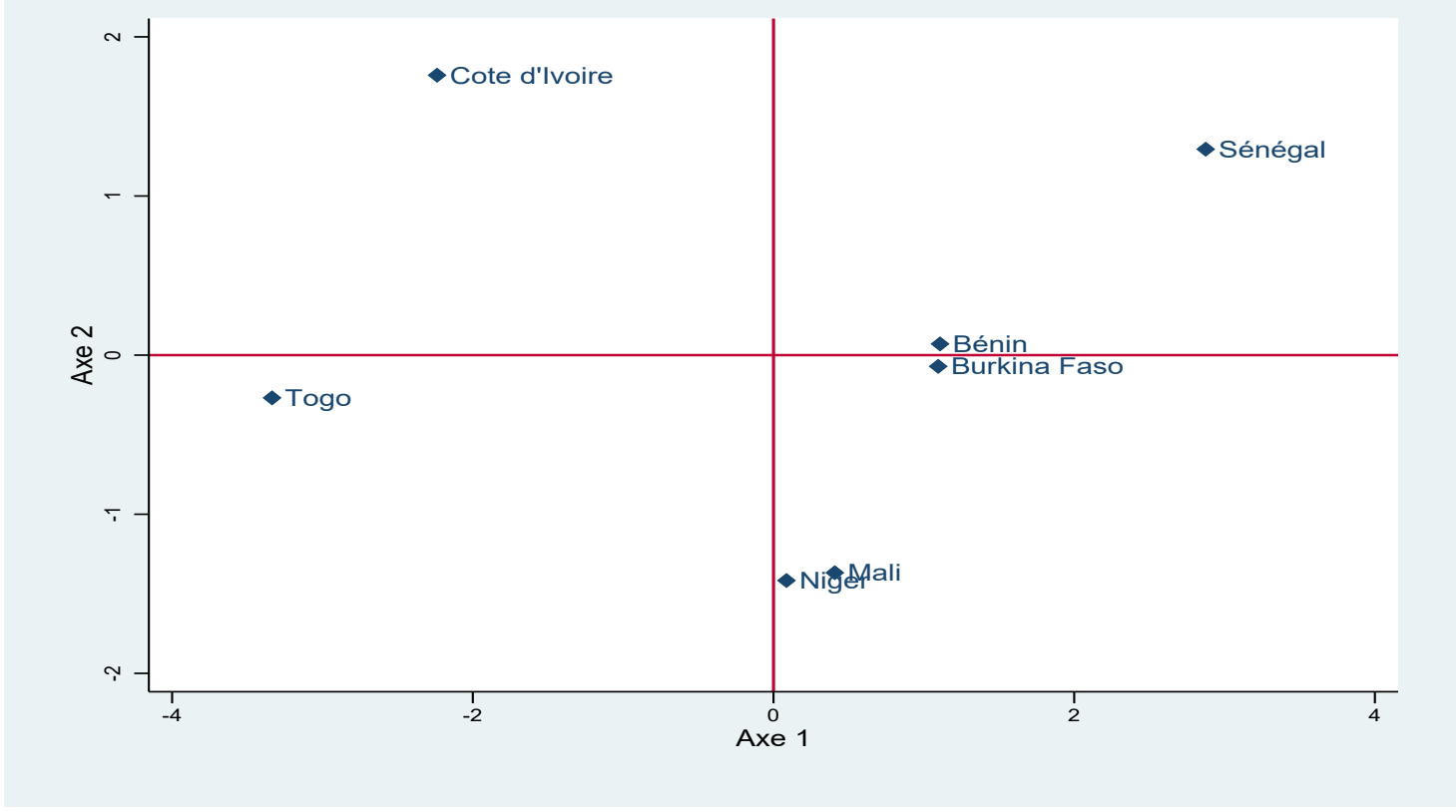

Figure 2. Cloud of individuals from PCA

variable is not significant $\left(\mathrm{P}_{i} \mathrm{t}=0.120\right)$, while all the other governance indicators and Income per capita are significant at the $5 \%$ threshold. The insignificance of this variable could be explained by the fact that in most of these countries in the zone, there is a permanent lack of compliance with laws and rules to act on air traffic. The two model validation tests according to the literature (Arellano and Blond's test for the non-correlation between AR(1) and errors, as well as the Sargan's overidentification test) as indicated by the table confirm the validity of the model.

\subsection{Determination of the Degree of Integration of the Model Variables}

As in all econometric modeling, unit root tests are a key step in the estimation procedure. The Duckey-Fuller tests are emphasized here to determine the order of integration of the variables. The procedure of these tests is briefly presented.

$H_{0}$ : Unit Root (Stationary) $H_{1}$ : No Unit Root (Stationary) $A D F$ : ADF Statistical Test (Dickey Fuller Augmented Test) $C V$ : Critical value

- If the $A D F$ value is lower than the $C V$ value then we accept the hypothesis $H_{1}$ : The $x$-series is stationary.

- If the $A D F$ value is greater than or equal to the $\mathrm{CV}$ value then we accept Hypothesis $H_{0}$ : The $x$ series is nonstationary.

It appears from the execution of the tests that all the variables are integrated of order $1(I(1))$. The results of these tests are presented in the appendix.

\subsection{Estimations of the Dynamic Model}

Firstly, it can be seen that air traffic in the countries of the zone depends on its past values. As can be seen from the table above, the history of the zone in terms of traffic has a positive influence on the current level of traffic. The national income per capita is also significant at the 5of people travelling by air is increasing. Thus this variable has a positive impact on traffic. This link could also be explained by the fact that the richer individuals become, the more business increases, especially in this context of regional integration. It also appears that voice and responsibility has a significant effect on air traffic for our sample. This could mean that the respect of democratic rules positively influences the traffic within the zone but also in each individual country. The contribution of political stability to the number of passengers per aircraft and per country in the zone is significant at the $5 \%$ threshold. This variable has a positive impact on air traffic and demonstrates that the political stability acquired by the countries in the zone since independence contributes to the explanation of our study variable. As for government effectiveness, it is significant at the 5\% threshold and has a positive impact on air traffic in the zone. This shows that government effectiveness plays a greater role in explaining the number of air travelers in each country. However, the three variables, namely the control of corruption and the quality of the government's performance, 
are not the same. regulation and compliance with the laws of the Republic are not significant at the $5 \%$ threshold in the WAEMU zone. This means that these variables have no impact on air traffic in the area. This is explained by the fact that corruption is an element that plagues the countries of this area and therefore has not yet reached the level of acting on national income and therefore on air traffic. Similarly, the insignificance could be explained by the fact that a large part of the companies in these countries operate in the informal sector and better yet, even to the public, there is really no effective control at the level of the administration. And therefore this variable cannot act on air traffic at the present stage. As for the laws of the Republic, in most of these countries, these laws are not respected, so the variable cannot have an impact on air traffic. This analysis shows that countries with high growth rates or very high per capita incomes, with a minimum of compliance with population laws and high governance scores are best suited to be considered as hubs.

Table 4. Results of Dynamic Elevation Model Estimates

\begin{tabular}{lr}
\hline & ln_traffic \\
\hline L.In_traffic & $0.275^{*}$ \\
ln (Rrevenu par habitant) & $1.108^{* * *}$ \\
Voice and Account & $-1.253^{* * *}$ \\
Political Stability & $0.479^{* * *}$ \\
Government Effectiveness & 0.166 \\
Regulatory Quality & 0.00539 \\
Rule of Law & 0.299 \\
Control of Corruption & $-0.585^{* *}$ \\
Constant & 0.457 \\
& $(0.22)$ \\
Observations & 90 \\
ar2 & 0.681 \\
sargan & 21.11 \\
hansen & 13.57 \\
\hline$t$ statistics in parentheses & \\
${ }^{*} p<0.05,{ }^{* *} p<0.01,{ }^{* * *} p<0.001$ & \\
\hline
\end{tabular}

\section{Conclusion}

In this article, we have examined an econometric model for the problem of locating an air hub for the area WAEMU. Governance has been understood by its six dimensions According to the Kaufman indicators and the level of air traffic, the data used come from the database of the WB. Our study To achieve this objective, proceeded first by a descriptive analysis which revealed the existence of a positive linear correlation between the governance indicators and the level of air traffic, then by a dynamic panel approach: A descriptive approach and an econometric approach. The descriptive method was based on a bivariate analysis, which made it possible to compare the countries in the sample according to the level of air traffic and the six governance indicators. These early trends were confirmed by the results of the econometric model, examining the contribution of governance to economic performance. In the constraints, we have introduces a constraint on political stability. Constraint who at our knowledge does not appear in the models proposed so far on the location of hubs. For the resolution, we built our database and we used the stata software to do the simulation. However, Senegal's behavior differs from that of the sample, and this in four dimensions of governance. Indeed, political stability, the effectiveness of government, regulatory quality as well as citizens' confidence in The country's rules and laws have a positive impact on per capita income and significantly contribute to considering Senegal as an enabling environment. It turned out that the optimal location of the hub is Dakar airport for a company in the WAEMU zone. As a hub can be moved for one reason or another, as a perspective we intend to make a model of a location of a hub which will take into account:

1. the cost of expanding airports

2. the capacity of the aircraft in the fleet

3. then we also plan to do a location model of two hubs.

\section{References}

Alumur, S., \& Kara, B. Y. (2007). Network hub location problems: The state of the art. Europian journal of operational research. 
CAMPELL, J. F. (1994). Integer programming of dicrete hub location problems. European Journal of Operational Research, 72, 387-405. https://doi.org/10.1016/0377-2217(94)90318-2

Contreras, I., Dias, J. A., \& ELENA, F. (2011). Branch and price for large-scale capacitated hub location problems with single assignment. INFORMS Journal on Computing, 23, 41-55. https://doi.org/10.1287/ijoc.1100.0391

Contreras, IVAN, Dias, J. A., \& ELENA, F. (2009). Lagrangian relaxation for the capacited hub location problem with single assignment. Regular Article, 31, 4835-05.

Diallo, C., MBAYE, N. B., \& SECK, D. (2012). Scheduling aircraft landings at lss airport. American Journal of Operations Research, 2, 235-241. https://doi.org/10.4236/ajor.2012.22027

Lapegue, T., Prot, D., \& Bellenguez-Morineau, O. (2013). Ordonnancement de personnel avec affectation de teches: un modele mathematique. In ROADEF.

Lapegue, T., Bellenguez-Morineau, O., \& Prot, D. (2013). A constraint-based approach for the shift design personnel task scheduling problem with equity. Computers and Operations Research, 40, 2450-2465.

https://doi.org/10.1016/j.cor.2013.04.005

O'KELLY, M. (1987). A quadratic integer program for the location of interacting hub facilities. European Journal of Operational Recherch, 32, 393-404. https://doi.org/10.1016/S0377-2217(87)80007-3

V Rodiguez, J., Alvarez, M., \& Barcos, L. (2007). Hub location under capacity constraints. Transportation Research Part E: Logistics and Transportation Review, 43, 495-505. https://doi.org/10.1016/j.tre.2006.01.005

Juan, C. M., \& Concepcion, R. (2004). Analyzing competition for hub location in intercontinental aviation markets. Transportation Research Part E, 40, 135-150.

\section{Annexe}

Table 5. Unit root test for Trafic

\begin{tabular}{lr}
\hline ADF regressions: 1 lags & \\
Statistic & p-value \\
W-t-bar 1.9156 & 0.9723 \\
\hline
\end{tabular}

Table 6. Unit root test for RNNHAB

\begin{tabular}{lr}
\hline Ho: All panels contain unit roots & Number of panels $=15$ \\
Ha: Some panels are stationary & Number of periods $=7$ \\
AR parameter: Panel-specific & Asymptotics: $T, N->+\infty$ \\
Panel means: Included & sequentially \\
Time trend: Not included & \\
ADF regressions: 1 lags & p-value \\
Statistic & 0.0000 \\
W-t-bar -6.7130 & \\
\hline
\end{tabular}

Table 7. Unit root test for VoiceAndAccount

\begin{tabular}{lr}
\hline Ho: All panels contain unit roots & Number of panels $=15$ \\
Ha: Some panels are stationary & Number of periods $=7$ \\
AR parameter: Panel-specific & Asymptotics: $T, N->+\infty$ \\
Panel means: Included & sequentially \\
Time trend: Not included & \\
ADF regressions: No lags included & \\
& Fixed-N exact critical values \\
Statistic & p-value 1\% 5\% $10 \%$ \\
t-bar -2.8940 & $-2.140-1.950-1.850$ \\
t-tilde-bar -1.8326 & \\
Z-t-tilde-bar -3.5642 & 0.0002 \\
\hline
\end{tabular}


Table 8. Unit root test for PoliticalStability

\begin{tabular}{lr}
\hline Ho: All panels contain unit roots & Number of panels $=15$ \\
Ha: Some panels are stationary & Number of periods $=7$ \\
AR parameter: Panel-specific & Asymptotics: $T, N->+\infty$ \\
Panel means: Included & sequentially \\
Time trend: Not included & \\
ADF regressions: 1 lags & p-value \\
Statistic & 0.0000 \\
W-t-bar -4.2310 & 0.000 \\
\hline
\end{tabular}

Table 9. Unit root test for GovernmentEffectiveness

\begin{tabular}{lr}
\hline Ho: All panels contain unit roots & Number of panels $=15$ \\
Ha: Some panels are stationary & Number of periods $=7$ \\
AR parameter: Panel-specific & Asymptotics: $T, N->+\infty$ \\
Panel means: Included & sequentially \\
Time trend: Not included & \\
ADF regressions: 1 lags & \\
De meme GovernmentEffectiveness est stationnaire & p-value \\
Statistic & 0.0011 \\
W-t-bar -3.0632 & \\
\hline
\end{tabular}

Table 10. Unit root test for RegulatoryQuality

\begin{tabular}{lr}
\hline Ho: All panels contain unit roots & Number of panels $=15$ \\
Ha: Some panels are stationary & Number of periods $=7$ \\
AR parameter: Panel-specific & Asymptotics: $T, N->+\infty$ \\
Panel means: Included & sequentially \\
Time trend: Not included & \\
ADF regressions: 1 lags & p-value \\
Statistic & 0.0056 \\
W-t-bar -2.5373 & 0.005 \\
\hline
\end{tabular}

Table 11. Unit root test for RuleofLaw

\begin{tabular}{lr}
\hline Ho: All panels contain unit roots & Number of panels $=15$ \\
Ha: Some panels are stationary & Number of periods $=7$ \\
AR parameter: Panel-specific & Asymptotics: $T, N->+\infty$ \\
Panel means: Included & sequentially \\
Time trend: Not included & \\
ADF regressions: 1 lags & p-value \\
Statistic & 0.0002 \\
W-t-bar -3.6133 & 0.002 \\
\hline
\end{tabular}

Table 12. Unit root test for ControlofCorruption

\begin{tabular}{lr}
\hline Ho: All panels contain unit roots & Number of panels $=15$ \\
Ha: Some panels are stationary & Number of periods $=7$ \\
AR parameter: Panel-specific & Asymptotics: $T, N->+\infty$ \\
Panel means: Included & sequentially \\
Time trend: Not included & \\
ADF regressions: 1 lags & p-value \\
Statistic & 0.0002 \\
W-t-bar -3.4948 & 0 \\
\hline
\end{tabular}


Table 13. Unit root test for D. Traffic

\begin{tabular}{lr}
\hline Ho: All panels contain unit roots & Number of panels $=15$ \\
Ha: Some panels are stationary & Number of periods $=6$ \\
AR parameter: Panel-specific & Asymptotics: $T, N->+\infty$ \\
Panel means: Included & sequentially \\
Time trend: Not included & \\
ADF regressions: 1 lags & p-value \\
Statistic & 0.0000 \\
W-t-bar -12.7635 & \\
\hline
\end{tabular}

\section{Copyrights}

Copyright for this article is retained by the author(s), with first publication rights granted to the journal.

This is an open-access article distributed under the terms and conditions of the Creative Commons Attribution license (http://creativecommons.org/licenses/by/4.0/). 